\title{
Evaluation of the Effect of Heart Failure Reversal Therapy (HFRT) on the Anthropometric Obesity Parameters in Patients of Chronic Heart Failure
}

\author{
Dr. Rohit Sane ${ }^{1}$, Dr. Gurudatta Amin ${ }^{2}$, Dr. Snehal Dongre ${ }^{3}$, Dr. Rahul Mandole ${ }^{* 4}$ \\ ${ }^{1}$ Department of Research and Development, Madhavbaug Hospital, Khopoli, India \\ ${ }^{2}$ Department of Clinical Operations, Madhavbaug Hospital, Khopoli, India \\ ${ }^{3}$ Medical Head, Madhavbaug Hospital, Khopoli, India \\ ${ }^{4}$ Department of Research and Development, Madhavbaug Hospital, Khopoli, India
}

*Corresponding author - Dr. Rahul Mandole

Received 14 February 2019;

Accepted 14 March 2019;

Published 26 March 2019;

\begin{abstract}
Background: Chronic heart failure (CHF) is a common cause of mortality and morbidity. Obesity influences the CHF development and prognosis. This study was conducted to assess effect of Heart failure reversal therapy (HFRT), a combination of panchakarma and allied therapies, on anthropometric parameters in CHF patients. Methodology: This retrospective study was conducted on data of patients who visited Madhavbaug clinics in Maharashtra, India between July-December 2018. Selection was based upon the availability of complete baseline (day 1 of HFRT) and follow-up data (day 30 of HFRT) of CHF patients who were admitted for minimum 5 days for HFRT. Results: Out of 147 patients, $74.15 \%$ were males with mean age $59.15+10.28$ years. There was statistically significant decrease $(\mathrm{p}<0.05)$ in both mean BMI and abdominal girth at day 30 of HFRT. 42 of 147 patients (28.57\%) had hypertension (HTN) with CHF, 22 patients (14.97\%) had diabetes mellitus (DM) and 61 patients $(41.49 \%)$ had both HTN and DM. In all these sub-groups, mean BMI and abdominal girth was significantly decreased $(\mathrm{p}<0.05)$ at day 30. Strong positive correlation was found between BMI and abdominal girth on day $1(\mathrm{R}=0.9, \mathrm{P}<0.05)$ and day $30(\mathrm{R}=0.83$, $\mathrm{P}<0.05)$ by Pearson's correlation. Similar correlation was found between the two parameters in subsets of CHF patients having HTN or DM or both DM and HTN ( $\mathrm{p}<0.05)$. Conclusion: HFRT decreased BMI and abdominal circumference significantly in CHF patients, irrespective of the presence of HTN or DM. Both the anthropometric parameters correlated strongly in all co-morbidity subsets of CHF patients.
\end{abstract}

Keywords: HFRT, Obesity, Body mass Index, Abdominal Girth, Comorbidity

\section{Introduction}

Globally, cardiovascular diseases (CVDs) are few of the commonest causes of morbidity and mortality and the picture in India matches the global scenario. In the true sense, CVD has become the commonest cause of death in the country. ${ }^{[1]}$ Chronic heart failure (CHF) is an intricate clinical syndrome which involves reduction in the ability of the heart to pump the blood in the systemic circulation or inability to fill itself appropriately with blood. ${ }^{[2]}$ Approximately 8-10 million Indians are suffering from $\mathrm{CHF}$, with an estimated prevalence of $1 \% .{ }^{[3]}$ There are well-known guidelines which talk about different pharmacological agents like angiotensin converting enzyme (ACE) inhibitors, angiotensin receptor blockers (ARBs), vasodilators as well as beta blockers for the management of CHF. However, despite these multiple treatment options, the CHF mortality in India is as high as $20 \%$ $30 \% .{ }^{[4]}$ Hence, there is a need of new treatment modalities which will improve the prognosis of CHF.
The role of obesity in the development or the CHF is widely debated. According to the Framingham Study there is an enhanced risk of developing CHF in people having elevated body mass index (BMI) (5\% risk in men and 7\% risk in women for every rising point of BMI). ${ }^{[5]}$ Though there are doubts over the role of obesity as a solitary risk factor in the CHF development as well as prognosis, it is a proved fact that obesity is associated indirectly or directly in the development of hypertension, type II diabetes mellitus and dyslipidemia, all of which are risk factors for $\mathrm{CHF}$ progress and development. ${ }^{[6]}$ Hence, there needs to be development of therapeutic options which can help control obesity, benefitting the patients of $\mathrm{CHF}$.

Physicians practicing alternative medicine believe that in the chronic stage of heart failure, use of panchakarma therapy (a 5step procedure for delivering internal body purification) is an effective add-on therapy ${ }^{[7]}$ Heart failure reversal therapy (HFRT), also known as sampurna hruyday shudhikaran (SHS) therapy, is a blend of herbal treatment with panchakarma and allied therapeutic 
modalities. ${ }^{[8-10]}$ The techniques utilized in HFRT include snehana (massage), swedana (passive heat therapy) and basti (medicated enema), which are known to free the body from the toxins.

There has been some recent published evidence on the effect of the HFRT therapy on CHF patients. However, there is a paucity of data on the specific effect of HFRT on the modifiable anthropometric parameters for obesity in the CHF patients, which are BMI and abdominal circumference. Though BMI is a commonly utilized parameter to monitor obesity in the population, it does not give information on the adipose tissue distribution in an individual. Abdominal obesity, which is indicated by waist circumference, plays a crucial role in the cardiovascular risk assessment. Major health organizations like World Health Organization (WHO) have also suggested the combination of BMI as well as abdominal obesity to determine the distribution of adipose tissue in a more profound way. ${ }^{[11]}$

In this retrospective study, the effect of HFRT was analyzed on BMI as well as waist circumference in CHF patients, to know the impact of HFRT on both the generalized body fat as well as on the abdominal obesity. We also assessed the correlation of the two anthropometric obesity parameters to check whether they go handin-hand, both before as well as after HFRT intervention.

\section{Methodology}

This was a retrospective study conducted on the data of the patients who visited the Madhavbaug clinics in Maharashtra, India between July 2018 to December 2018. The data of only those patients was considered who had been administered HFRT over minimum 5 days of admission in the Madhavbaug clinics. Cases were identified, and data was assessed from the medical records of Madhavbaug clinics in Maharashtra. The selection was based upon the availability of complete relevant baseline data (day 1 of HFRT) and follow-up data (day 30 of HFRT) of the patients. The information about co-morbidities, if any, were noted down from the medical records.

The HFRT is an amalgamation of panchakarma as well as allied therapies. HFRT uses different oils and decoctions, which constitutes of a 4 -step procedure, described below in table 1 .

Table 1: Study Treatment: Heart Failure Reversal Therapy (HFRT)

\begin{tabular}{|c|c|c|c|}
\hline Step of HFRT & Type of Therapy & Herbs used for therapy & Duration of Therapy \\
\hline Snehana & $\begin{array}{l}\text { Massage or external oleation } \\
\text { (centripetal upper strokes } \\
\text { towards heart) }\end{array}$ & $\begin{array}{l}10 \text { grams T. arjuna, } 10 \text { grams Dashamoola and } \\
5 \text { grams V.negundo } \\
{[100 \mathrm{ml} \text { extract processed in sesame oil }]}\end{array}$ & 30-35 minutes \\
\hline Swedana & Passive heat therapy & $\begin{array}{l}\text { Dashmoola (group of ten herbal roots) with } \\
\text { steam at } \leq 40 \text { degrees Celsius) }\end{array}$ & $\begin{array}{l}10-15 \text { minutes }+3-4 \text { minutes } \\
\text { of relaxation after procedure }\end{array}$ \\
\hline Hrudaydhara & $\begin{array}{l}\text { Decoction dripping therapy from a } \\
\text { height of } 7-8 \mathrm{~cm}\end{array}$ & Luke-warm dashmoola decoction & 15 minutes \\
\hline Basti & $\begin{array}{l}\text { Medicated enema administered per- } \\
\text { rectal, should be in body for } \geq 15 \\
\text { minutes for maximum absorption }\end{array}$ & $\begin{array}{l}1.88 \text { grams } T . \text { arjuna, } 0.42 \text { grams } B . \text { diffusa } \text { and } \\
0.18 \text { grams } A . \text { calamus } \\
\text { [10 } \mathrm{ml} \text { aqueous extract }]\end{array}$ & 10 minutes \\
\hline
\end{tabular}

On the first day of hospital admission before starting HFRT, the BMI was evaluated by taking into consideration the height and the weight of the patients and using the formula: weight in kilograms/(height in meters) ${ }^{2}$. The abdominal girth of patients was measured on day 1 before initiating HFRT using a measuring tape and noted down in medical records. In a similar way, the measurements of height, weight and abdominal girth were done on day 30 from HFRT initiation and the comparison with the baseline $\mathrm{BMI}$ and abdominal girth was done.

Data was entered and coded in Microsoft Excel spreadsheet. Graphpad Instat software was used to analyze the data. Categorical data were represented in the numeric form and continuous data were presented as the mean $\pm \mathrm{SD}$. Paired t-test was used to assess the difference between the values at baseline and 30th day after treatment initiation. Correlation between BMI and abdominal girth was calculated using Pearson's correlation coefficient. P value < 0.05 was considered statistically significant.

\section{Results}

A total of 147 patients' data was included in the study for analysis. The demographic details were compiled, and it was found that majority of the patients were males $(74.15 \%)$. The mean age of the CHF patients was 59.15 years, with a mean baseline weight of 69.21 kilograms and mean height of 1.6 meters (Table 2).

Table 2: Demographic Details of CHF Patients ( $n=147)$

\begin{tabular}{|l|l|}
\hline Mean age (years) & $59.15 \pm 10.28$ \\
\hline Median age (years) & 59 (Range: $30-80)$ \\
\hline Number of males & $109(74.15 \%)$ \\
\hline Number of females & $38(25.85 \%)$ \\
\hline Mean baseline weight $(\mathrm{kg})$ & $69.21 \pm 14.39$ \\
\hline Mean baseline height (meter) & $1.6 \pm 0.08$ \\
\hline
\end{tabular}

On comparing the mean BMI of all CHF patients between day 1 and day 30 of HFRT treatment, there was statistically significant decrease, assessed by paired $T$ test. Similar findings were noted for mean abdominal girth, with statistically significant decrease at day 30. 42 of the 147 patients $(28.57 \%$ ) had hypertension (HTN) associated with CHF, 22 patients (14.97\%) had type II diabetes mellitus (DM) and 61 patients (41.49\%) had both HTN and DM along with CHF. In all these sub-groups, the mean BMI and mean abdominal girth was found to be significantly decreased at day 30 compared to that on day 1 . (Table 3 ) 
Table 3: Change in Anthropometric Obesity Parameters in Patients of CHF based on co-morbidities

\begin{tabular}{|l|l|c|c|c|}
\hline & & Day l of treatment & Day 30 of treatment & P value \\
\hline \multirow{2}{*}{ All CHF patients [N=147] } & Mean BMI (kg/m2) & $26.69 \pm 4.97$ & $25.16 \pm 5.05$ & $0.01 *$ \\
\cline { 2 - 5 } & Mean Abdominal girth $(\mathrm{cm})$ & $98.82 \pm 12.74$ & $93.68 \pm 12.36$ & $0.01 *$ \\
\hline $\begin{array}{l}\text { CHF with Hypertension (HTN) } \\
{[\mathrm{N}=42]}\end{array}$ & Mean BMI (kg/m2) & $26.67 \pm 4.61$ & $25.09 \pm 5.05$ & $0.01 *$ \\
\cline { 2 - 5 } & Mean Abdominal girth $(\mathrm{cm})$ & $98.05 \pm 11.67$ & $93.19 \pm 11.69$ & $0.01 *$ \\
\hline $\begin{array}{l}\text { CHF with Diabetes mellitus } \\
(\mathrm{DM})[\mathrm{N}=22]\end{array}$ & Mean BMI (kg/m2) & $25.73 \pm 6.46$ & $24.46 \pm 6.25$ & $0.01 *$ \\
\cline { 2 - 6 } & Mean Abdominal girth $(\mathrm{cm})$ & $96.45 \pm 15.47$ & $91.44 \pm 14.96$ & $0.01 *$ \\
\hline $\begin{array}{l}\mathrm{CHF} \text { with both HTN and DM } \\
{[\mathrm{N}=61]}\end{array}$ & Mean BMI $(\mathrm{kg} / \mathrm{m} 2)$ & $27.34 \pm 4.83$ & $25.66 \pm 5.44$ & $0.01 *$ \\
\cline { 2 - 6 } & Mean Abdominal girth $(\mathrm{cm})$ & $101 \pm 12.9$ & $95.79 \pm 12.35$ & $0.01 *$ \\
\hline
\end{tabular}

$P<0.05$ considered significant by Paired T test

On calculating the correlation between BMI and abdominal girth separately on day 1 and day 30, strong positive correlation was found between the two anthropometric parameters, as represented in figures 1 and 2.

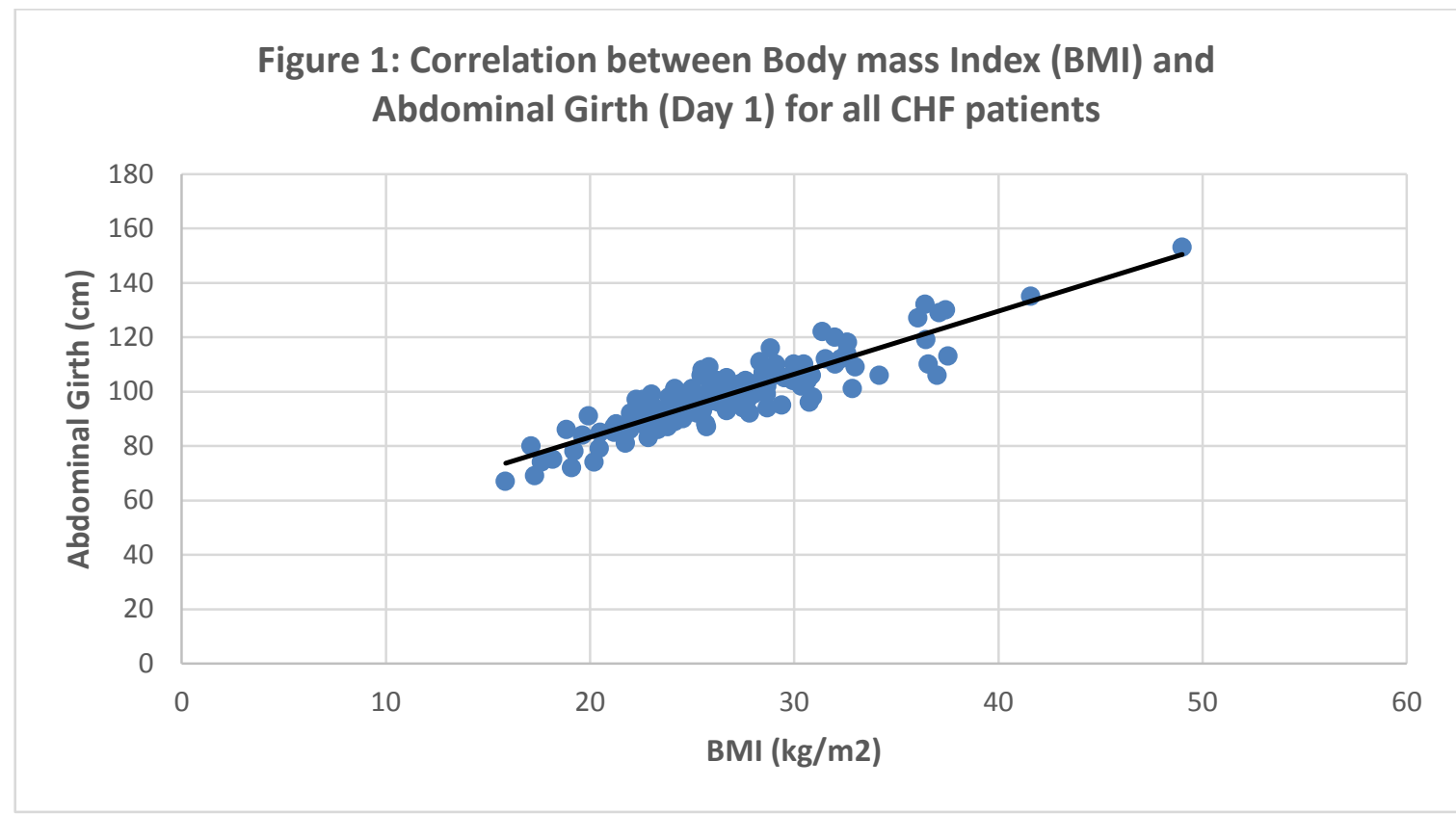

s Pearson Correlation Coefficient: $\mathrm{R}=0.9$ (Strong correlation)

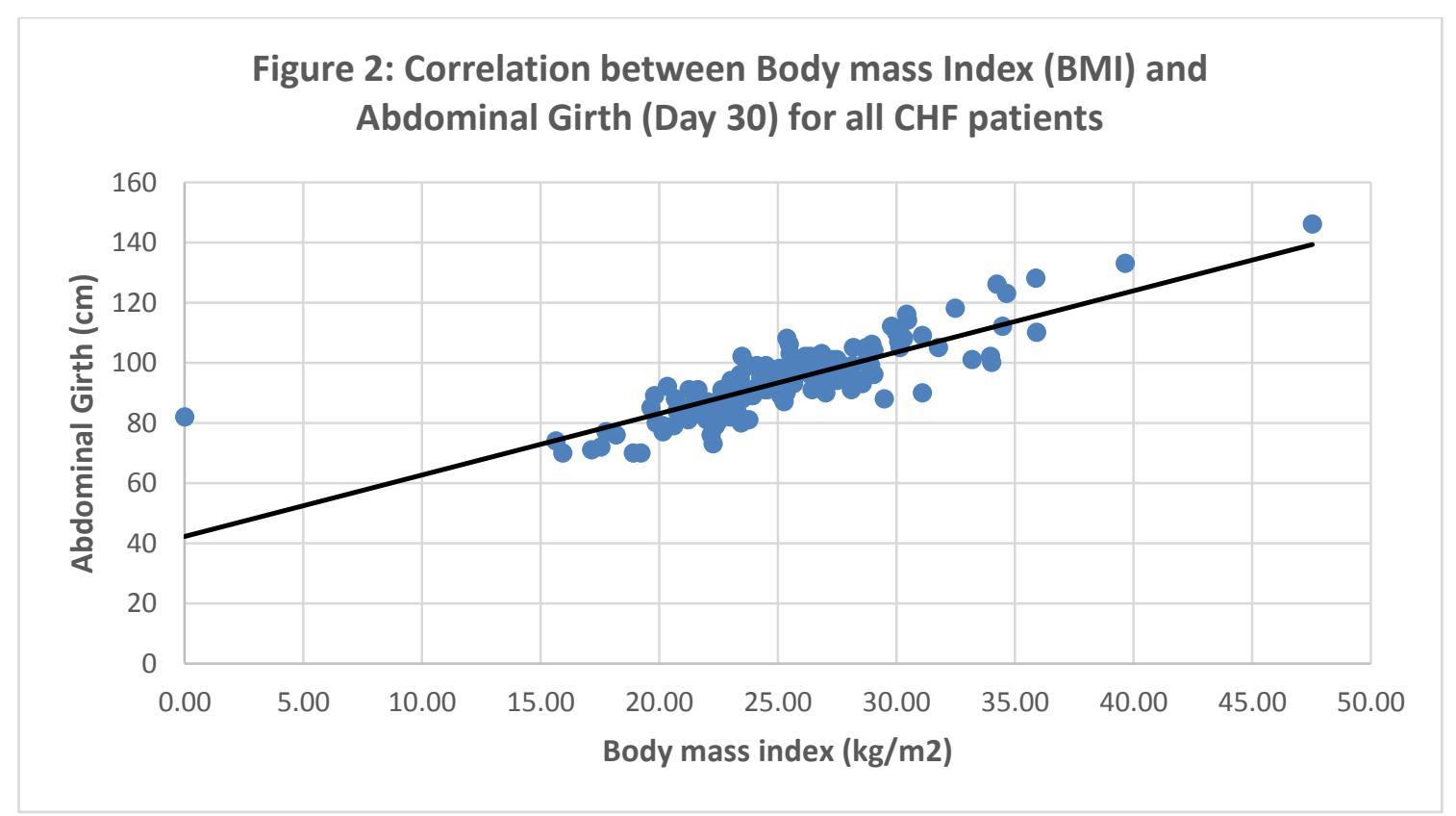

Pearson Correlation Coefficient: $\mathrm{R}=0.83$ (Strong correlation)

On subgroup correlation analysis based upon the associated co-morbidities, we found strong correlation between BMI and abdominal girth in subsets of CHF patients having only HTN, only DM or both DM and HTN, and all these correlations were statistically significant. 
Table 4: Correlation between BMI and Abdominal girth in patients of CHF with various co-morbidities

\begin{tabular}{|l|l|c|c|c|}
\hline \multirow{2}{*}{ Day of assessment } & Comorbidity seen & $\begin{array}{c}\boldsymbol{R} \text { (Correlation } \\
\text { coefficient) }\end{array}$ & Interpretation & $\boldsymbol{P}$ value \\
\hline \multirow{5}{*}{ Day 1 of HFRT } & All CHF patients [N=147] & 0.9 & Strong positive correlation & $<0.01^{*}$ \\
\cline { 2 - 5 } & CHF with Hypertension $(\mathrm{HTN})[\mathrm{N}=42]$ & 0.85 & Strong positive correlation & $<0.01^{*}$ \\
\cline { 2 - 5 } & CHF with Diabetes mellitus $(\mathrm{DM})[\mathrm{N}=22]$ & 0.94 & Strong positive correlation & $<0.01^{*}$ \\
\cline { 2 - 5 } & CHF with both HTN and DM [N=61] & 0.91 & Strong positive correlation & $<0.01^{*}$ \\
\hline Day 30 of HFRT & All CHF patients [N=147] & 0.83 & Strong positive correlation & $<0.01^{*}$ \\
\cline { 2 - 5 } & CHF with Hypertension $(\mathrm{HTN})[\mathrm{N}=42]$ & 0.8 & Strong positive correlation & $<0.01^{*}$ \\
\cline { 2 - 5 } & CHF with Diabetes mellitus $(\mathrm{DM})[\mathrm{N}=22]$ & 0.95 & Strong positive correlation & $<0.01^{*}$ \\
\cline { 2 - 5 } & CHF with both HTN and DM $[\mathrm{N}=61]$ & 0.8 & Strong positive correlation & $<0.01^{*}$ \\
\hline
\end{tabular}

Correlation coefficient calculated by Pearson correlation test, $p<0.05$ considered significant

\section{Discussion}

Obesity poses as a risk factor for multiple CVDs, prominent of which are CAD and CHF. BMI is considered as an important indicator of sedentary lifestyle as well as impending or prevalent obesity. Many studies have shown that CHF patients having high BMI are at an increased risk of mortality. ${ }^{[12,13]}$ Abdominal obesity, indicated by calculating the abdominal girth, is associated with development of multiple metabolic diseases like HTN and DM. These metabolic diseases are known risk factors for not only the development of $\mathrm{CHF}$ but also alters the prognosis. Hence, measuring of the anthropometric obesity indicators, which are BMI and abdominal girth, are equally important to predict the development or prognosis of CHF.

The existing treatment modalities have positive effects on the cardiovascular parameters but when it comes to their effect on BMI or abdominal girth, none of the drugs of CHF are known to be affecting them. There is certainly a dire need of modalities which can help modify these anthropometric parameters, which may directly and indirectly help in making the CHF prognosis more positive. Physicians practicing alternative medicine utilize panchakarma therapy as an add-on therapy for treatment of CHF and HFRT is a combination of panchakarma with allied therapies. ${ }^{[9]}$ However, the effect of HFRT on the specific anthropometric parameters in patients of CHF are not well established, and no study has taken the co-morbidities besides CHF into consideration. Hence, it was thought to evaluate the effect of HFRT on BMI and abdominal girth in CHF patients, and also analyze the data based on the subgroups suffering from HTN or DM or both.

In this study, we assessed the effect of HFRT, a novel treatment modality, in CHF patients, on the obesity parameters of BMI and abdominal girth, after 30 days of HFRT initiation. It was found that HFRT significantly lowers the BMI and abdominal girth at day 30 , compared to the baseline. The sub-group analysis to assess the effect of HFRT in CHF patients suffering from DM and HTN, separately and together, yielded positive results. This was done to evaluate whether any underlying metabolic disease will affect the positive effect of HFRT on the anthropometric measurements, which was not the case. Hence, irrespective of the underlying metabolic disease of HTN and DM, HFRT may benefit the patients based on BMI and abdominal girth.

HFRT comprises of Snehana (external oleation or massage), Swedana (passive heat therapy), Hridaydhara (decoction dripping therapy) as well as Basti (per rectal drug administration). Published literature states that the sympathetic nervous system is activated in obesity. ${ }^{[14]}$ It has been theorized that Snehana decreases the sympathetic activity of the body, which may be one of the factors which may be decreasing the body fat. Swedana involves exposure of the body to external heat, which is believed to decrease the subcutaneous body fat. Stress is a common factor which is associated with increasing BMI as well as obesity which may be tackled by Hridaydhara, which leads to patient relaxation both mentally as well as physically. According to a published research on obese patients, Basti moderates the immune responses by controlling the pro-inflammatory cytokines, immunoglobulins and functional properties of T-cells. These alterations are associated with a reduction in the body weight. ${ }^{[15]}$

BMI does not discriminate between the fat mass and fat-free mass, which is an accepted indicator of the general health status. The robustness of BMI as an adequate obesity indicator is not proved in elderly individuals, as the fat-free mass decreases with age. ${ }^{[16]}$ Waist circumference or abdominal girth helps in determining abdominal adiposity, which is a better indicator of risk to develop various metabolic diseases. By checking the correlation between BMI and abdominal circumference, it was proved that irrespective of the associated co-morbidity with CHF, HFRT significantly decreases general body mass as well as on abdominal adiposity, which correlated well in all subgroups of CHF patients.

The study had a few limitations. The study assessment was done only after 30 days of HFRT, so long term effects of HFRT on the anthropometric parameters was not assessed. The study was of retrospective design, and so was dependent on the availability of patient data. Future research over a longer study period and with a prospective study design may be planned to generate more evidence for effect of HFRT on anthropometric measurements.

\section{Conclusion}

HFRT decreased BMI and abdominal circumference significantly in patients of CHF, irrespective of the presence of any other co-morbidity like HTN or DM. Both the anthropometric parameters correlated strongly in all the co-morbidity subsets of CHF patients.

\section{Acknowledgements:}

The authors thank the study participants and their families, without whom this study would not have been accomplished. We would also like to acknowledge Dr. Kritarth Naman Singh for medical writing.

\section{References}

[1] Prabhakaran D, Jeemon P, Roy A. Cardiovascular Diseases in India. Circulation. 2016;133(16):1605-20. 
[2] Coronel R, de Groot JR, van Lieshout JJ. Defining heart failure. Cardiovasc Res. 2001;50:419-22.

[3] Seth S. Heart Failure in India: Need for Indian Guidelines. Cardiological Society of India. Accessed from www.csi.org.in/Cardio_pdf/21.pdf on 6th February 2018.

[4] Seth S, Ramakrishnan S, Parekh N, Karthikeyan G, Singh S, Sharma G. Heart failure guidelines for India: Update 2017. J Pract Cardiovasc Sci 2017;3:133-8.

[5] Kenchaiah S, Evans JC, Levy D. Obesity and the risk of heart failure. New Engl J Med 2002;347:305-13.

[6] Gierach M, Gierach J, Ewertowska M, Arndt A, Junik R. Correlation between Body Mass Index and Waist Circumference in Patients with Metabolic Syndrome. ISRN Endocrinology 2014;1-6.

[7] Mishra LC, ed. In: Scientific basis for ayurvedic therapies, September. CRC Press; 2003.

[8] Vinjamury SP, Vinjamury M, Sucharitakul S, Ziegler I. Panchakarma: ayurvedic detoxification and allied therapies - is there any evidence? In: Evidence-based practice in complementary and alternative medicine. Berlin, Heidelberg: Springer; 2012:113-137.

[9] Mandole R, Sane R. A retrospective cohort to study the mortality and survival rate amongst chronic heart failure (CHF) patients after Ayurvedic Sampurna Hruday Shudhikaran (SHS) therapy. J Clin Exp Cardiol. 2015;6:4.

[10] Sane R, Hanchate M. Effect of the Sampurna Hriday Shuddhikaran (SHS) model in heart failure patients in
India: a prospective study. $\mathrm{Br} \mathrm{J}$ Med Med Res. 2014;4(1):564.

[11] Shields M, Tremblay MS, Connor SG, and Janssen I. Abdominal obesity and cardiovascular disease risk factors within body mass index categories. Health Reports. 2012; 23(2):7-15.

[12] Martinez S, Byku M, Novak E, Cedars A, Eghtesady P, Ludbrook $\mathrm{P}$ et al. Increased Body Mass Index Is Associated with Congestive Heart Failure and Mortality in Adult Fontan Patients. Congenital Heart Disease. 2015;11(1):71-9.

[13] Aune D, Sen A, Norat T, Janszky I, Romundstad P, Tonstad S, Vatten LJ. Body Mass Index, Abdominal Fatness, and Heart Failure Incidence and Mortality: A Systematic Review and Dose-Response Meta-Analysis of Prospective Studies. Circulation. 2016;133(7):639-49.

[14] Davy KP, Orr JS. Sympathetic nervous system behavior in human obesity. Neurosci Biobehav Rev. 2008;33(2):116-24.

[15] Thatte U, Kulkarni A, Ghungralkar R, Panchal F, Vetale $\mathrm{S}$, Teli $\mathrm{P}$ et al. Immunological \& metabolic responses to a therapeutic course of Basti in obesity. Indian Journal of Medical Research. 2015;142(1):53-62.

[16] Chinedu SN, Ogunlana OO, Azuh DE, Iweala EEJ, Afolabi IS, Uhuegbu CC et al. Correlation between body mass index and waist circumference in Nigerian adults: implication as indicators of health status. Journal of Public Health Research 2013; 2(e16):93-98. 